\title{
Eric Snodgrass
}

\section{DUSK TO DAWN: HORIZONS OF THE DIGITAL/POST-DIGITAL}

APRJA Volume 3, Issue 1, 2014 ISSN 2245-7755

CC license: 'Attribution-NonCommercial-ShareAlike'. 


\section{Blue - the most popular color on the Internet}

The equipment-free aspect of reality here has become the height of artifice; the sight of immediate reality has become a blue flower in the land of technology."

(Walter Benjamin, "The Work of Art in the Age of Mechanical Reproducibility" 35)

Consider the blue flower. Its cold, unnatural luminescence. Its role in the German tradition of Novalis et al as absorptive placeholder for romantic longings, prop and stand-in for a striving towards an ungraspable, infinite beyond. A call to the horizon. Its relative rarity in nature and sense of otherworldliness. How in pure sunlight blue fades and thus the blue flower's preferred habitat in the threshold moments of dusk and dawn, when it is possible to observe the Purkinje effect, the temporary shifting of the processing of colour perception from the central cones of the fovea to the more sensitive rods of the retina's periphery, the disappearing sunlight slowly draining warmer, long wavelength colours of their lustre while giving the cooler, shorter bands of the spectrum a heightened luminosity in the moody twilit hues of what is known as "the blue hour."

And what of a certain strand of colourinformed anthropocentrism? The marked craving within some cultures for more fully saturated colours which the "meagrely endowed" (Finlay 402) natural palette of this planet's bounty of less vivid browns and greens seemingly fails to satisfy. The way in which such a craving finds expression via an ongoing supplementation of this seeming lack in the form of an ever increasing synthetic range of often strikingly saturated man-made colours, each trying to catch the eye of the second sun that is the human visual cortex in ever more heliotropic stimulation.

How in the age of "digital media" and the internet, it would seem that a certain blue luminosity has never been far from reach. Since the days of the very first hyperlinks, blue as the underlining signifier and promise of further horizons of interaction. Those many synthetic blues of technology. Chroma key blue, signifier of a world predestined for post-production. The post-crash blue screen of death. The default "Bliss" wallpaper of Windows XP, one of the most widely embedded images of the digital age, with its pacifying blue-green pastoral... ah, the supreme flattery of Graphical User Interfaces and this particularly memorable "topography of pure departure" (Harpold 239). A fig leaf of an image.

Tech logo blue. Facebook blue. Soothing, corporate IBM deep blue. The chirpy, social pastel of Twitter blue and the vaguely translucent gradients of iOS 7 blue. A showy blue LED. The engineer's metonymical accentuation, asserting a certain "technology-ness of technology" (Shedroff and Noessel 43). Blue, blinking Bluetooth, blue. Saturated glow of the digital and its attention economy. Ethereal stimulant and banal sedative. Blue pill.

So many blue avatars of the digital, flowering all around, each striving both to stand out and still fit in at the same time. Such is the seeming ubiquity of blue in the land of technology today and this little prelude is intended simply to give a sense of how it can be seen to serve as an "index of the zeitgeist" (Jameson 69), a signifier of the viscous spread of the the digital, its ubiquity and sense of givenness. A blue digital banality to which the post-digital might partly be a reaction towards.

As digitally inflected practices and technology become further diffused and 


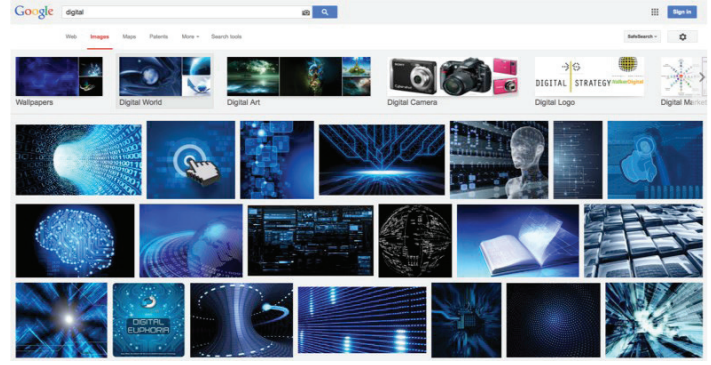

Google image search for 'digital' (11 Nov 2013).
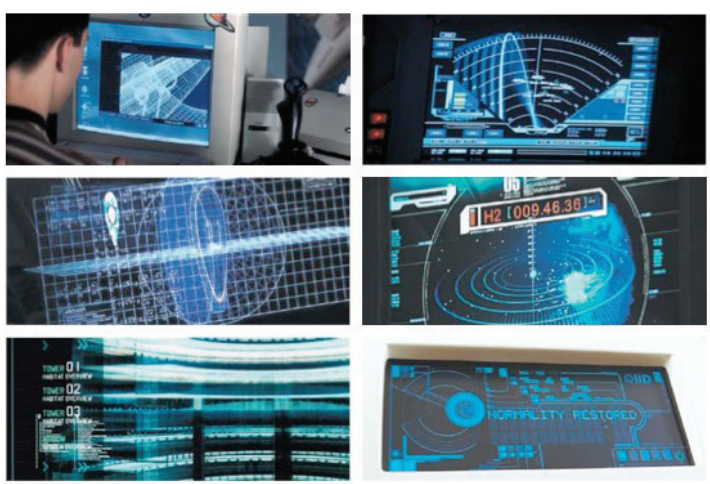

Future screens are mostly blue' - from Shedroff and Noessel's (41-2) study of computing interfaces in sci-fi films and television. The histograms on the right 'were made by selecting representative images for each screen-based interface in the survey, filtering out noninterface elements in the scene, aggregating them into a single image, and running a Photoshop analysis on the result.'

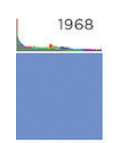

1980
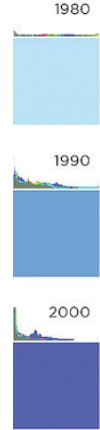

2007

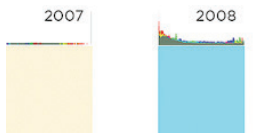

Shedroff and Noessel (41-2)
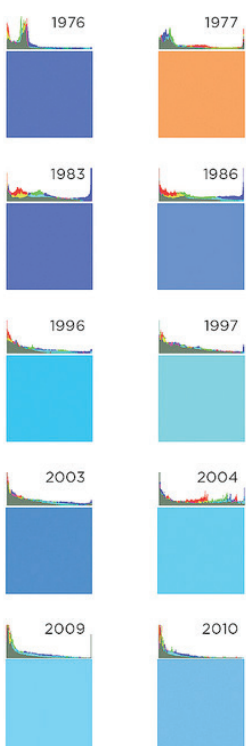

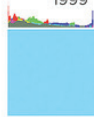

2005

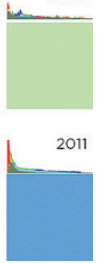

1999

1989

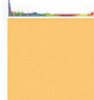
egregiously construed. Nevertheless, it will be suggested that this very matter of fact yet elusive nature of the digital, its status as a kind of affective, theoretical "confound" such as Brian Massumi (174-5) speaks of, might be understood as being one of its defining modalities and also possibly a key symptom of any transitioning moves towards a condition or practice of the post-digital. 
In this vein, one might already suggest an initial answer to the question of "why blue?" Given that, as Florian Cramer ("What is Post-digital?") points out, the colloquial meaning of the digital is highly metonymical in nature, perhaps there is a similar metonymical quality to blue - everybody's favourite colour - that makes it such a ready partner to the digital. The grasping, affective viscosity and fuzziness of each. The horizon that is blue and the promise that has been the digital. Also, their telling, liminal glow. Massumi (239): "It starts with the glow. Or the "too-' of the blue."

\section{Blue Hours}

at dusk, it is the way the colour sinks among us, not like dew but settling dust or poisonous exhaust from all the life burned up while we were busy being other than ourselves.

(William Gass, "On Being Blue" 59)

As a preformative affix that will lay waste to its stem, the prefix of post- can be seen as signifying a recognition (and even premediation) of collapse. Perhaps it is partly intended to mark out another site of "so many ontological cave-ins," similar to that which Rosalind Krauss (290), in her essay "Reinventing the Medium," speaks of in relation to photography's saturation into mainstream, everyday ubiquity. Drawing on Walter Benjamin's notion of the "outmoded" object, Krauss describes that particular moment of temporal limbo for a medium in which it takes on a status as outdated but not quite fossilised into what Hertz and Parikka call the "archaeological phase" of a product's lifecycle (429). Krauss (295) christens this in-between phase "the twilight zone of obsolescence." In such a zone the outmoded object may be seen to cast what Benjamin (Selected Writings 209) describes as the "profane illumination" of its own afterlife, radiating an immanent and potentially critical afterglow, both on its own form and out at the various mythologies it once helped to project. By dint of its quality as impotent, denuded and ultimately discarded, the no longer valuable, outmoded object can for Benjamin (The Arcades Project, 466 [B1a, 4]) act as a powerful "anti-aphrodisiac," a palette cleanser that unsettles the once highly entangled and mediated relationship with the object in question. In the case of a media object, its provisional status as medium - an apparatus with various well- or loosely-defined technical, social, aesthetic, material, economic, institutional, idealogical and other factors that inform its everyday uses - the moment of obsolescence can be said to shed a certain light on these relations in the sense of their very disappearing into thin air, and noticeable, felt absence. One is reminded of Marshall McLuhan's (24) vivid evocation of that transitory moment of visibility that occurs when a previously dominant mode of understanding is made obsolescent by a newly mediated form of understanding: "Just before an airplane breaks the sound barrier, sound waves become visible on the wings of the plane. The sudden visibility of sound just as sound ends is an apt instance of that pattern of being that reveals new and opposite forms just as the earlier forms reach their peak performance." Death becomes the medium, technology, object.

"Death" here is the obsolescence, the subsidence or outright collapse of the relational vitality and sense of the mediated significance of the item under consideration, and a "blue hour" simply any instance in which a kind of temporal afterglow of this release from mediation is experienced. In their book Life after New Media - Mediation as a Vital Process, Sarah Kember and Joanna Zylinska (55) stress the importance of understanding 
mediation as "primarily a temporal, multiagential phenomenon, a process rather than a spatialized and spatializing object." Thus a particular media form is for Kember and Zylinksa (67) a sustained instance of a temporary "fixing" or "stabilization" of the originary, emergent and ongoing "vital process" of mediation itself. In this sense we might understand the process of obsolescence as being a draining of the relational vitalities of a particular medium, a process that might also offer up an illuminating afterglow, in which the still felt absence of this vitality reminds us how, "Every medium thus carries within itself both the memory of mediation and the loss of mediations never to be actualized" (Kember and Zylinksa 21). Or, as Eric and Marshall McLuhan (227) define it, the obsolescence of a medium is characterised by the way in which it mobilises a shift towards an "awareness of ground as all potential."

One potential in temporarily dwelling on such onsettings of obsolescence is for how they might prove conducive for tracing the contours of any particular condition of post-. Blue hours can be understood as providing a setting of relatively heightened atmospherics, in which mediation itself can be said to subtly flex the curvature of its horizon in a just noticeable fashion. At such moments, in such a zone, one might more readily make out some of the many blended rays that inform a given situation, with any kind of noticeable resistance in the overlapping ecologies involved potentially making certain aspects of such an encounter temporarily distinct and sensate.

As hinted at above, a blue hour of obsolescence might well be compared to the "afterglow" of this year's Transmediale theme (Transmediale 2014), with its evocation of "the intense red glow of the atmosphere long after sunset (or long before sunrise), when most twilight colours should have disappeared. The afterglow is caused by dust in the high stratosphere, which catches the hues of the twilight arch below the horizon." One should of course tread carefully in the kind of dramatic theoretical scenes that evocative writers like Benjamin so tantalisingly set, but at the very least, one might be on the lookout for this particular scene of obsolescence, a transition period that might occasionally provide lucid, uncanny or prescient modes for perceiving the previously pervasive or oversaturated qualities of certain mediated entities in question, before these too eventually subside again as residue back into the more generic atmospherics of mediation, inevitably playing a role, large or small, in the various ecologies that designate visibility, mass, time, space, velocity, value.

\section{Anamorphosis, or, the backwards glance}

Blue hours such as these suggest an aspect of something that was always there, awaiting its release. A capacity for rebirth that something like obsolescence, in various guises, can act as thanatological ground for. Of particular interest from the perspective of how a notion of post-digital can be of conceptual and/or aesthetic use is how, in the kind of taking in of a blue hour of obsolescence described above, there is the potential for a relational and critical encounter. Just as the second acts of post-modernism or post-colonialism recast that which came before them in a renewed light, so too might an invocation of post-digital restage an encounter with the notion of digital that comes before it. This is the sense of a backwards glance that a blue hour and the first moments of recognition or response thereafter can release, an enactment of a looking-in-the-(rear-view)-mirror moment which the obsolete or post-digitally 
renewed entity can set into motion.

In order to give a name to this evasive yet potentially emergent quality, one might draw from various discussions on anamorphosis, the optical technique of transposing a distorted projection within and according to the norms of the visual logic of linear perspective. In its most usual form, the anamorphic image requires that the viewer adopt a particular viewing angle or viewing device in order to reconstitute and better make out the enclosed anamorphic image (the iconic example of this technique being Hans Holbein the Younger's 1533 painting The Ambassadors). By virtue of its relatively common application in covertly enclosing memento mori ("remember that you will die") style death-related imagery, and as an embedded signifier of the workings of the media practice in question, anamorphosis can be understood here as a technique and concept that highlights the emergent potentials of obsolescence and post- via the way that it can hint at both the ephemerality and seeming limits of media practice, while also indicating towards other horizons, such as the seemingly innate capacity of images, objects, concepts and mediation itself to escape again one's ability to grasp, let alone unify, their dynamic potentialities.

In its extending of the rules of linear perspective towards seemingly quirky or absurd effects, anamorphosis is "a continual reminder of the astonishing and artificial elements in perspective" (Baltrušaitis 2). By dint of its very excessive yet perfectly reasoned execution, it highlights the general tricks of the trade of Euclidean perspective and that "excess of zeal" on the part of man, whose arts and technologies seem so focused on "supplementing Nature's error" (Chantelou, cited in Baltrušaitis 2). In a similar vein, one might recall those metonymical blues of technology. The excess in supplemental, affective zeal that blue would seem to signify in today's technological context and which a simple Google image search of "digital" will reveal, in anamorphic fashion, as having always been there.

One site of interest here is the uncomfortable proximity that post- hints at, the lingering, umbilical connection between the progenitor and its late coming prefix, which the embedded quality of the anamorphic also highlights. How anamorphosis is able to act as a potentially unsettling augur embedded within a taken for granted norm, employing the same tools of the media technique in question to create further indexical yet awry scenes which can tease out the very artificial, even absurd nature of the everyday perspective in question. Such signallings of a kind of resistant, "anamorphic remainder" (Boluk and LeMieux), in their very dormant yet persistent fashion, can be experienced as an alternative, potentially alien nature that returns and confronts the mediating and mediated subject with the primacy and weird nature of its own uncanny contortion acts.

Jacques Lacan's (Four Fundamental Concepts; Ethics) various writings on anamorphosis are worth turning to in such a context, particularly for the way in which his conception of anamorphosis alerts one to this sense of lingering alienation that is embedded and closer in the mirror than it appears. A potentially disturbing proximity that hints at topological structures of the self which further Lacanian concepts such as the Real similarly addresses. In a Lacanian register, one can turn to the spectre of the profane illumination of the obsolete media object and speak of how this illumination can be partly experienced as a gaze of the temporarily illuminating object, by virtue of the way in which those many scopic rays of desire are experienced as being reprojected back out from the obsolete object in question. The "pulsatile" (Lacan, Four Fundamental Concepts 89) afterglow of these possessive, saturated drives casting 
a dark shadow, presenting the "annihilating subject" (Four Fundamental Concepts 84) with a jilted reflection of the structures and ideologies which the object has been moving between, is mediated by and yet can be seen to always potentially resist or withdraw from. The way in which these newly presenced drives of the subject might be said to be temporarily turned "inside-out" (Lacan 82), before escaping again, accelerating or decelerating towards the vanishing points of yet further investments of this desire.

Can we ever really be post-? Think of Jean-François Lyotard, in his "Note on the Meaning of 'Post-'", reflecting back on a term that ended up taking on such a life of its own (The Postmodern Explained 80): "You can see that when it is understood in this way, the 'post-' of 'postmodern' does not signify a movement of comeback, flashback, or feedback - that is, not a movement of repetition but a procedure in 'ana-': a procedure of analysis, anamnesis, anagogy, and anamorphosis that elaborates an 'initial forgetting." Is it a surprise that many link the rise of the post-digital with a return of the ana- of analogue? Sealed within the black box, gift wrapped in the sales pitch, enclosed in every discovery is the embedded promise of forgetting.

If the descriptions of blue hours and a flexing of the curvature of mediation in the previous section seemed rather crytpo-mystical turns of phrase, one might further recall Lyotard's description of what is happening at the origin moment of the Renaissance's rediscovery of linear perspective, the mother of all demos that was Filippo Brunelleschi's early $15^{\text {th }}$ century linear perspective experiment carried out, in its most famous iteration, in front of the octagonal structure of Florence's Baptistery of St. John. As Lyotard (Discourse, Figure 180) points out, the seductive success of linear perspective, as so vividly presented by Brunelleschi in his painted wood panel, peephole and mirror demonstration, is achieved by "the effect of blocking out the peripheral field, thus of 'decurving' perceptual space and rendering it as consistent as possible with the central focal area where the curvature (the anamorphosis) is negligible." Anamorphosis, by virtue of its introduction of a shifted, diverging point of view that nevertheless simultaneously plays within the rules of linear perspective, can be understood as enacting a kind of liminal recurving of the scene of linear perspective's particular form of mediation. Similarly, in its reengaging with elements of a perceived "pre-" or "non-" digital nature, the post-digital might partly be understood as an attempt to dislodge or at least curve what can be thought of as more irrepressibly linear, homogenising natures - which the digital and the many related factors that help to manifest it continue to so readily latch onto. By virtue of its introduction of an alternative to the singularity of a given vanishing point, the anamorphic, like obsolescence, indicates towards a potential for "poetic reversal" (Lyotard, Discourse, Figure 377 ). In the case of post-digital, there is the simple reversal that even just the term itself enacts via its initiating of a renewed focus which it casts on the slippery, pervasive qualities of the digital. Similarly, some postdigital practices might partly act as mirrors or transduction devices for remembering, rethinking or repurposing current notions and manifestations of the digital.

\section{\#banality}
No one really dreams any longer of the Blue Flower. Whoever awakes as Heinrich von Ofterdingen today must have overslept. [...] No longer does the dream reveal a blue horizon. The dream has grown gray. The gray 
coating of dust on this is its best part. Dreams are now a shortcut to banality. (Walter Benjamin, "Dream Kitsch Gloss on Surrealism" 236)

In his writing on surrealism and kitsch, Benjamin (Writings on Media 236-38) highlights how the Surrealists, in their crosshatching of the dream world with the objects, furnishings and "cheap maxims" of the everyday, "are less on the trail of the psyche than on the trade of things." At the pinnacle of such a practice, "the topmost face on the totem pole is that of kitsch. It is the last mask of the banal, the one with which we adorn ourselves, in dream and conversation, so as to take in the energies of an outlived world of things." In the face of its own unsettling anamorphic alterity and obsolescing drive, the digitally inflected subject has shown an impulsive readiness to latch onto the banal. Online meme ecologies, with their compressed, easily circulated qualities, readily co-evolve with technological provisions such as network bandwidth constraints, instantly replicable digital formats, the highly-greased and quickly churning gears of social media platforms and so on. They partake of a naturalised "trade of things" in the digital, providing a replicable, utilitarian vernacular of rough and ready image macros that can serve as express circuits to banality.

Now almost a decade on since Tim O'Reilly's formulating of the rise of "Web 2.0," in the mainstreaming of things like usergenerated 4chan memes into daily morning news shows and Facebook wall posts, there has for some time been detectable a sense of popular, collective self-awareness - "Oh Internet" - in regards to this saturation of the digital. It would seem that we are all producers of "internet-aware art" (Guthrie Lonergan, in McHugh 10) now, and everything is now potentially possessed with a degree of understanding from the digital, to the point where saying so carries little value. Is any kind of "blue spill" of the digital even noticed anymore? Each discrete part, each ecology, readily overlaps on the other. And overlaps, and overlaps. In such a condition, the emphasis seems no longer to be on startling juxtapositions of everyday objects such as the Surrealists were after, but rather in the increasingly natural, i.e. banal, overlap of what might previously have been experienced as unnatural.

Nevertheless, in something like the popular surge towards the accessible photo filters of Instagram, one might delineate a kind of, part defence mechanism, part tactical countering at play in its employment of the masking device of the filter. At the beginning of such a potential shift towards the post-digital, there is the much commented upon way in which the applying of a photo filter casts an artificial aesthetic of age and materiality upon these digital images, a visual shorthand of saturation and pinhole effects that hints back to pre-digital photographic practices that involved lengthy exposure times and hands-on engagement with the analogue prints and chemicals of the darkroom. This applying of a kind of layer of "fauxstalgia," such as media scholar and practitioner Talan Memmott is outlining in his writing on "banality based banality," helps to mask something like the selfie in sufficiently profane, analogue-esque illumination. In its purposely streamlined interface for postproduction, Instagram can be seen to readily service what Lacan (Four Fundamental Concepts 104) characterises as a taming of the gaze (dompte-regard), in this case, the gaze of the subject as it is reflected back in the typically hypermediated modality of the digital, lending a more palatable slant via this mask of the Instagram filter, its reintroduction of an obsolescent aesthetic and its slight but mandatory temporal pause for a moment post-production reflection. 
At the same time though, while the digital filter may add aesthetic value and meaning for the user, it is also infused with a degree of banality as a result of the difficult to ignore sense of artificiality that becomes almost immediately visible when a user returns to their photo stream and is likely (particularly in the early use of Instagram) to be confronted with example after example of this filtered aesthetic, any analogue aura quickly being drowned out in the return to the mise en abyme like hall of mirrors of easily replicable and painlessly disseminated digitality. As one sees in this anamorphic-style return, the reoccurent drive finds yet another ready partner in the digital. Lacan again (Ethics, p.136): "At issue, in an analogical or anamorphic form, is the effort to point once again to the fact that what we seek in the illusion is something in which the illusion as such in some way transcends itself, destroys itself, by demonstrating that it is only there as a signifier." In the subsequent rise in the practice of tagging non-filtered pictures on Instagram with a \#nofilter tag one starts to see a suggestive edging towards a post-digital tipping point, an indication of a heightened sense of awareness on the part of Instagram's users in regards to this subsuming banality of the digital, acknowledged here via the backwards glance of this knowing hashtag.

With so-called invasive technifictation looking more and more like a ubiquitous banal given (whose terms of reference were apparently signed off on long ago), little wonder then the appeal of an apotropaic mask of the banal that can attempt to at least partly assuage and apply some taming filters, quotation marks or hashtags upon such potentially alienating qualities, which at times may for its users feel like undergirding, emanating forces of the "always-on" technologies of today. The iconic black mirrors of moment: the drone, the anamorphic gaze of machine vision, Google Glass, the soon to be ubiquitous
3D printed "blobject," internet-aware soldiers and their streams of Instagram selfies and endlessly looping Vines - an oscillating and/or, this intimate/mundane portraiture of the war machine. Likewise, it is always worth recalling the way in which institutions of power, digitally born and otherwise, often adopt a certain strategically cosmeticised veneer of the banal, with their cheery doodles and seemingly plain vanilla shopfront windows, the wolf in sheep's clothing tactic. If anything, in the contemporary landscape even the anamorphic itself might serve as yet another potential mask of the banal with which to adorn one's personal or institutional brand. Thus, perhaps, the trendings of H.P. Lovercraft referencing memes, weird Twitter and "that exciting new Google creepiness that's just creepy enough for 2014" (Sterling).

In response to the viscous spread of the digital, its seeming horror vacui ("fear of empty space") and kitsch-like lack of restraint and drive to cover every niche and corner with its own internet of things, why not adopt the recycling tactic of a banal ecology (or garbology) of memes in which one can make oneself at home in, or indeed tactically mask other manoeuvres within? As a result of its own strong levelling power, in which all things are fair game ("ask me anything"), banality can also be said to establish a certain democratic plateau for the internet "junk" that it gleefully recycles. Similar to anamorphosis, it too retains a power to cut through, to interpenetrate such layers of existence and extinction. The still paroxysmal primacy of laughter that a meme can unearth. The silent, unstoppable force of animated GIFs. Boredom and its unexpected, emergent capacities.

One might posit the banal and anamorphic as a kind of dual, interconnected pairing, in a similar vein to Bolter and Grusin's (355-6) formulation of the psychology of remediation, with its "double logic" and twinned desires for 
immediacy and hypermediacy (the elusive quality of immediacy being not dissimilar to that of the evasive, horizon dwelling blue flower in the land of technology and the anamorphic as a compulsive, hypermediate return). Similarly, something like the \#nofilter meme on Instagram might quickly be tagged as representative of just another example of the vernacular, reflexive style play of postmodernism. Yet the filter and the \#nofilter might also be seen as enacting a critical reflection of sorts on mediation and digital practice, and in so doing, potentially opening the gates towards post-digital practice. Indeed, by virtue of their ready participation in the everyday trade and vernacular of the digital, such seemingly banal practices have a certain knack for plucking out the cultural markers of the contemporary moment that are felt to be of particular communicative power, and in which one can often sense an embedded, self-aware and even implied or charged critical commentary within. A criticality or sense of awareness that might, on occasion, be able to gather certain kinds of counter-publics or movements around their resonant momentum.[1] In this very active exchange of the banal in the digitally informed ecologies of the moment there seems to be a lingering theme of resistance and even resilience on the part of the digitally informed media objects and their users. That ongoing potential for resistance embedded in the stubborn medium or object that, when viewed from a particular angle or caught in a particular relational juncture, can act as, not so much the longed for blue flower, but rather "anti-aphrodisiac" or antidote for reencountering the dominant, obsolete and/ or everyday ecologies in which various entities are able to extend across or reposition against.

\section{Bewersdorf blue}

In 2008, Kevin Bewersdorf initiated his digital performance piece PUREKev, a work that might serve as a brief example of a transitional blue hour of obsolescence that touches on some of the themes of this paper. The plan of execution for the work was noticeably barebones. Over the course of three-years (2008-11) an automated performance would play out, in which a looping animated GIF of over-exposed home video footage depicting a flickering firecracker would very gradually diminish over time, extinguishing at a provisionally imperceptible but steady rate for its visitors, gradually becoming a field of "pure" blue. PUREKev was initiated in tandem with Bewersdorf's decision to delete as much of the existing archive of his work as he could from the Internet. In fact, as far as one can tell, Bewersdorf was largely successful in this endeavour and his online archive is today notably difficult to unearth, despite the best efforts of interested admirers and archivists. Thus the auto-destructive nature of the piece was not simply a one off, relatively old hat conceptual gesture, but rather a committed embrace on the part of this net-based artist to fully extract his artistic output from the digital - particularly coming as it did at a time when Bewersdorf's star looked to be on the rise. As Gene McHugh (40) writes of PUREKev in his book Post-Internet, "The website goes in the exact opposite direction of most Internet production, focusing on slow, imperceptible change over the course of years. By doing so, it allows one to see (as if for the first time) what it opposes." In the piece, it is the blue void rather than the flame that acts as the main performer, surrounding its increasingly pitiable flame, pushing it down and with each passing day forcing us to scroll, and scroll, and scroll, hunting for a figure, no matter how fleeting, that might release us from 
this amorphous ground, the "MAXIMUM SORROW" that is Bewersdorf blue.

"MAXIMUM SORROW" is the logo with which Bewersdorf brands many of the images and characters of his melodrama, an anamorphic, memento mori style reminder and imprint of the dot-com crash of an earlier moment in the digital imaginary and the Totentanz, post-crash condition of "2.0." It shows up in several of the pieces in his Monuments to the INFOspirit series, suggesting a bubble burst, a feeling of the blues or burnout that emanates in a vaguely atmospheric fashion throughout much of Bewersdorf's works. One is reminded of Krauss (291-2) speaking of photography's transition from an exciting new medium to yet another commodity that was "swallowed by kitsch," a transition that partly "betrays a social class under siege." Expanding on Benjamin's classic reading of photographer Eugène Atget in "The Work of Art..." essay, Krauss (292) points out how Atget's photographs can be read as a kind of antidote to the "fraudulent mask of art" in the photography of the time: "Atget's response to this artiness is to pull the plug on the portrait altogether and to produce the urban setting voided of human presence, thereby substituting, for the turn-of-the-century portrait's unconscious mise-en-seine of class murder, an eerily emptied 'scene of a crime."'

In these pieces by Bewersdorf one witnesses a somewhat similar aesthetic manoeuvre in their pulling of the plug of the digital (and perhaps even an outlining of a crime scene of sorts). Within this vacuum of the outmoded there is also the sense of a lingering afterglow of the pervasive, corporate INFOspirit that clearly once inflated the drama of its digitally inflected subjects while also seeming to drain them of a certain sense of vitality. In his "The Four Sacred Logos" text, produced as a series of brochures for reading at the Monuments to the INFOspirit exhibit, Bewersdorf (88) is able to channel a certain banal pulse and undercurrent of the digital age: "Maximum Sorrow is a way of perceiving and accepting this sense of drowning we all feel as we spiral with the whirlpool of info towards mediocrity. It is sorrowful to accept that mediocrity resides in each of us. It is sorrowful to realise that mediocrity is at the limits of our awareness." The text includes "Mediocrity Awareness Exercises," short marketing style mantras of text, sound and image for rehearsing as one browses through Bewersdorf's denuded, pathetic, entirely mediocre physical objects, hollowed-out yet still emotive materialisations of a life online. Mediocrity is presented here not so much as a placebo but rather as remedy or even ritualistic, anagogical transitional vehicle for attempting to tune in to the full force of that anamorphic other of the works, the unreachable, uncontainable INFOspirit.

It is also hard to miss the reoccurring use of blue throughout these works, which here seems turned inside out in a poetic reversal that acts in its own way as a kind of binding call to the horizon or vanishing point - "a sensitive spot, a lesion, a locus of pain, a point of reversal of the whole of history" (Lacan, Ethics 140) - an abstract but resonant signifier of the digital against which Bewersdorf can offset and perform a world of banal, overlapping, almost sacrificial obsolescence.[2]

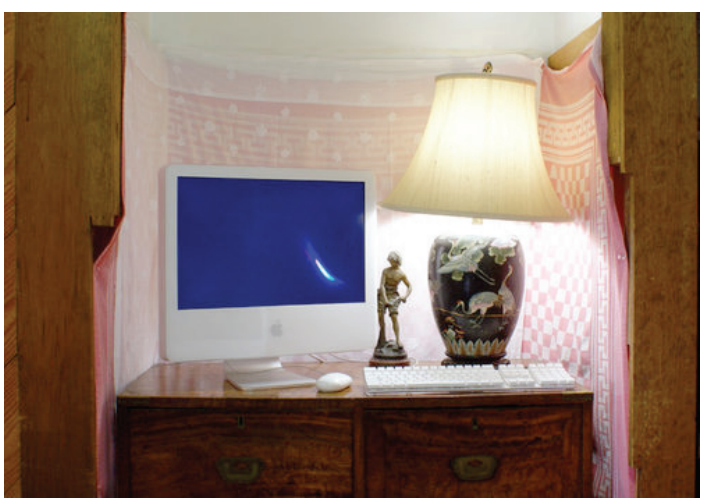

Kevin Bewersdorf, Still Life with Blue Flame, 2008. 


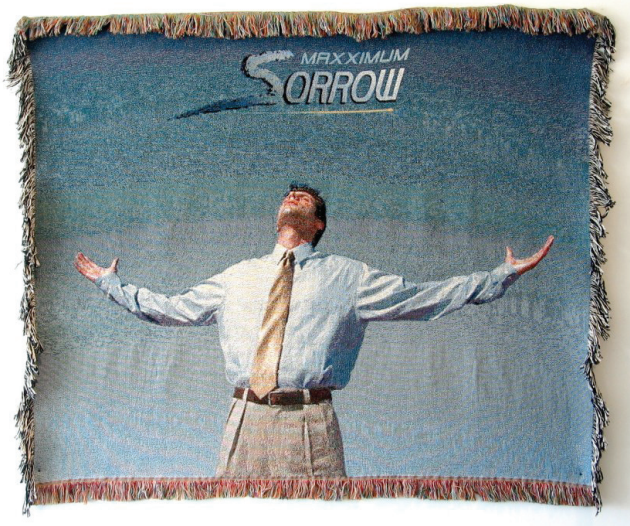

Kevin Bewersdorf, Maximum Sorrow throw rug, 2007.

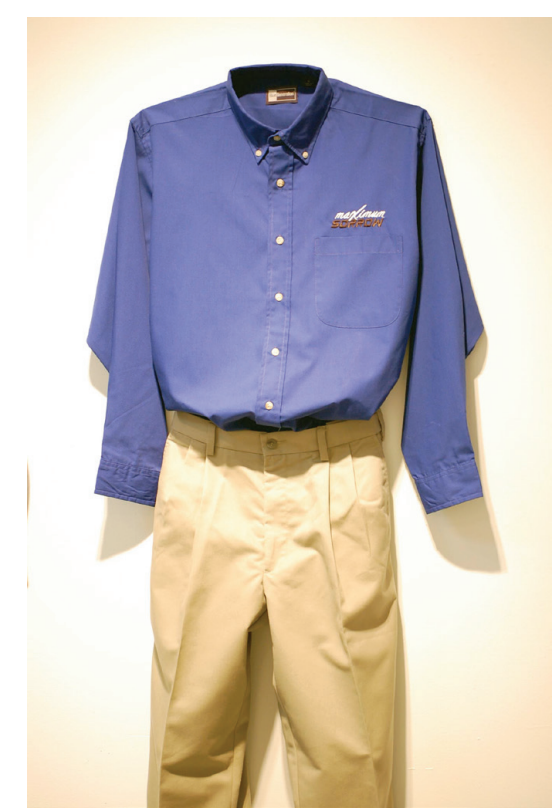

Kevin Bewersdorf, Monuments to the INFOspirit, 2008.

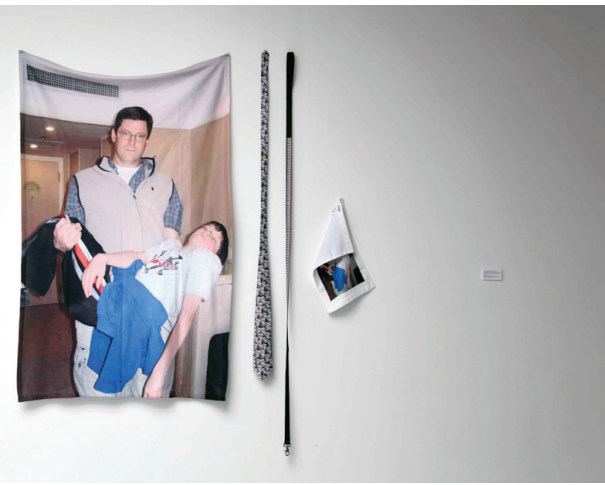

Kevin Bewersdorf, Google Image Search Result for 'Exhausted' Printed onto Blanket, Tie, Dog Leash and Golf Towel by Walgreens.com, 2009.

\section{Blue Flower?}

\author{
Is the internet dead? This is not a \\ metaphorical question. It does not \\ suggest that the internet is dysfunc- \\ tional, useless or out of fashion. It asks \\ what happened to the internet after it \\ stopped being a possibility." \\ (Hito Steyerl, "Too Much World: Is the \\ Internet Dead?")
}

Why blue? Why post-digital? This paper began with a riffing on blue and its status as a meme-like signifier of the digital, a readymade scaffolding and prevalent filter of the digital imaginary. Having initially indicated towards the romantic conceit of the blue flower, the question returns now as to whether the post-digital is itself a conceptual blue flower? Indeed, can something as nebulous as "the digital" even be treated in a remotely similar manner to an object or a medium? Can it really become obsolete or post-? Ins Blaue hinein... At each turn, this very emulsive, ever-proliferating nature of the digital seems to both cling to and yet elude one's grasp.

Undoubtedly this is in part an issue relating to the particularly burdensome imposition that a prefix like post- puts on an already sufficiently problematic stem, reminding one of Frederic Jameson's grapplings with the confounding "total flow" of postmodernism and "how the thing blocks its own theorisation, becoming a theory in its own right" (Jameson 71). One would also do well to keep in mind the reactive, self-propagating nature that such theoretical manoeuvres can readily get carried away by. At least the simple sounding of a speculative death knell of post- in relation to the digital, rather than positing it as any kind of definitive term, might act in a similar way to the onset of obsolescence, the suspending quality of its hyphen creating a temporary tension, a zone of uncertainty 
or wobble that might somewhat unsettle the stem that it still implicitly admits it cannot necessarily escape from, nor even wants to. The title of Cramer's recent talk on the matter, "Post-digital: a term that sucks but might be useful," gives some indication of these kinds of strands that come into play.

In exploring themes of onsetting obsolescence, anamorphic alterity and quotidian banality, a central point here has been to emphasise the way in which, in this postPRISM revelations present, there seems to arise a renewed or heightened sense of awareness and reflexivity in relation to many of the digitally informed practices of today. A kind of sobering moment in which one is reminded, yet again, of how so many blue horizons and promises of the digital end in yet more false dawns. And furthermore, how in such a transitional instance the potential arises for a shifting in approach or a cleansing of a misguided or overused palette. One that might turn our attention to other significant shadings in the media spectrum, such as a much needed interrogation of the more indiscernible, uniform and unremitting "gray immanence" of "evil media" that Fuller \& Goffey highlight (13-4). Or likewise, in considering the temporal and immanent qualities of media that obsolescence highlights, one might, as the likes of Hertz and Parikka have outlined, excavate post-digital blueprints for an ethico-aesthetic DIY practice that is able to respond to the embedded post- of planned obsolescence, with its environmental saturation of obsolete technologies whose relative material permanence endows them with an extended afterlife in which they may be rediscovered, recycled, remixed, reinterpreted. Enacting a shift in focus from the illuminating qualities of immanent or recently occurred death, to that of the never-really-dead "untimeliness" of "media undead" (Wolfgang Ernst, cited in Hertz and Parikka 429). From dusk to dawn. The sun also rises. To trace out and get hands on with the kinds of horizons of speculation and everyday encounters that the post-digital proposal, in an interventionalist modality, might nudge into relational or resistive being. 


\section{Notes}

[1] An obvious example to point to in this context would be the spread in usage of the so-called "Guy Fawkes" mask: from its initial adoption by children in the late 18th century, who would display masked effigies of Fawkes while begging for money on Bonfire Night, to its later resurfacing in the cult 1982-89 comic series $V$ for Vendetta, and subsequent crossover into popular culture with the 2006 film adaptation of the comic and its $\$ 6.99$ Halloween costume replica of the mask sold as a merchandising tie-in to the film. In the same year, use of the mask spread further via the $/ \mathrm{b} /$ message board of 4chan (and other imageboards) in the guise of the popular "Epic Fail Guy" meme, whose hapless eponymous stick figure was often depicted wearing the mask. Around 2008, the use of the mask migrated into association with protest movements, beginning with the Anonymous movement's donning of the mask during a series of protests against the Church of Scientology and then spreading internationally and into mainstream consciousness with the outbreak of the 2011 Occupy protests and its regular use at these and other rallies since then. The Guy Fawkes mask as meme oscillates back and forth in a dance with the multiform qualities of the banal, vaguely menacing yet entirely familiar, demonstrating its potential as provider of a mask of anonymity, a break from more singular forms of identity, and/or a compositing and refortification of identity, whether this be in the realms of counterculture, marketing and/or the proto-political.

[2] An aside, while it appears that Bewersdorf has continued to remain off the grid of the net art scene since PUREKev, he has gone on to stake out a promising career as both actor and soundtrack composer in the mumblecore film circuit. His most recent appearance, in the acclaimed Computer Chess (2013), has him in the role of "cameraman," a character whose role it is to amble about within the film's homage to the early days of artificial intelligence, awkwardly recording the events of the fictional computer chess tournament with a Sony AVC-3260, black-and-white analogue tube camera (originally manufactured in 1969). The film itself was shot on the same camera, with the help of a retrofitted analogue to digital video signal converter and hard drive, and is full of the kind of celebration of anamorphic banality that one finds in Bewersdorf's earlier net art pieces. Is there a more fitting existing example of a post-digital career trajectory?

\section{Works cited}

Baltrušaitis, Jurgis. Anamorphic Art. tr. W.J. Strachan. Ann Arbour: Chadwyck-Healey Ltd, 1976. Print.

Benjamin, Walter. Selected Writings, Volume 2, Part 1, 1927-1930. tr. Rodney Livingstone et al. Cambridge, MA: Harvard University Press, 1999. Print.

Benjamin, Walter. The Arcades Project. tr. Howard Eiland and Kevin McLaughlin. Cambridge, MA: Harvard University Press, 2002. Print.

Benjamin, Walter. The Work of Art in the Age of Its Technological Reproducibility, and Other Writings on Media. tr. Edmund Jephcott, Rodney Livingstone, Howard Eiland, and Others. Cambridge, MA: Harvard University Press, 2008. Print. 
Bewersdorf, Kevin. Spirit Surfing. Brescia: LINK Editions, 2012. Print.

Bolter, Jay David and Richard Grusin. Remediation - Understanding New Media. Cambridge, MA: MIT Press, 2000. Print.

Boluk, Stephanie and Patrick LeMieux. "Stretched Skulls: Anamorphic Games and the memento mortem mortis." Digital Humanities Quarterly, Vol. 6, No. 2 (2012). Web. http://www.digitalhumanities.org/dhq/ vol/6/2/000122/000122.html

Cramer, Florian. "What is "Post-digital"? post-digital research blog, 14 Dec (2013). Web. http://post-digital.projects.cavi. $\mathrm{dk} / \mathrm{p}=295$

Finlay, Robert. "Weaving the Rainbow: Visions of Color in World History." Journal of World History, 18.4 (2007): 383-431. Print.

Fuller, Matthew and Andrew Goffey. Evil Media. Cambridge, MA: MIT Press, 2012. Print.

Galloway, Alexander. "10 Theses On The Digital." 8/31 (2012). Web. <https://vimeo. com/48727142>

Gass, William. On Being Blue - A philosophical inquiry. Boston: David R. Godine, 1976. Print.

Harpold, Terry. Ex-foliations: Reading Machines and the Upgrade Path.

Minneapolis: University of Minnesota Press, 2009. Print.

Hertz, Garnet and Jussi Parikka. "Zombie Media: Circuit Bending Media Archaeology into an Art Method." Leonardo, Vol. 45, No. 5 (2012): 424-430. Print.
Jameson, Frederic. Postmodernism, Or, The Cultural Logic of Late Capitalism. Durham: Duke University Press, 1991. Print.

Kember, Sarah and Zylinksa, Joanna. Life after New Media - Mediation as a Vital Process. Cambridge, MA: MIT Press, 2012. Print.

Krauss, Rosalind E. "Reinventing the Medium." Critical Inquiry, Vol. 25, No. 2, "Angelus Novus": Perspectives on Walter Benjamin (1999): 289-305. Print.

Lacan, Jacques. The Four Fundamental Concepts of Psychoanalysis, Seminars of Jacques Lacan, Book XI. tr. Alan Sheridan. London: W W Norton \& Company, 1998. Print.

Lacan, Jacques. The Ethics of Psychoanalysis 1959-1960, Seminars of Jacques Lacan, Book VII. tr. Dennis Porter. London: W W Norton \& Company, 1992. Print.

Lyotard, Jean-François. Discourse, Figure. tr. Antony Hudek and Mary Lydon. Minneapolis: University of Minnesota Press, 2011. Print.

Lyotard, Jean-François. The Postmodern Explained: Correspondence, 1982-1985. Minneapolis: University of Minnesota Press, 1993. Print.

Massumi, Brian. Parables for the Virtual - Movement, Affect, Sensation. Durham: Duke University Press, 2002. Print.

McHugh, Gene. Post-Internet: Notes on the Internet and Art 12.29.09>09.05.10. Brescia: LINK Editions, 2011. Print. 
McLuhan, Marshall. Understanding Media - the extensions of man. Corte Madera:

Gingko Press, 2003. Print.

McLuhan, Marshall \& McLuhan, Eric. Laws of Media - The New Science. Toronto:

University of Toronto Press, 1988. Print.

Memmott, Talan. "Fauxstalgia." Banality

Based Banality blog, UnderAcademy

College (2013). Web. <http://bbbanality.

wordpress.com/2013/03/18/fauxstalgia/>

Shedroff, Nathan and Christopher Noessel.

Make It So - Interaction Design Lessons

from Science Fiction.Brookly, NY: Rosenfeld

Media, 2012. Print.

Sterling, Bruce. "Design Fiction: Nymi by Bionym." Beyond the Beyond blog, Wired, 29 Dec, 2013. Web. <http://www. wired.com/beyond_the_beyond/2013/12/ design-fiction-nymi-by-bionym/>

Steyerl, Hito. "Too Much World: Is the Internet Dead?" e-flux journal 49 (2013).

Web. <http://www.e-flux.com/journal/ too-much-world-is-the-internet-dead>

"Transmediale 2014." Transmediale, n.d. 02 Dec (2013). Web. <http://www.transmediale. de/festival> 